\title{
How Many Roles Can Children Play?
}

\section{Monica Landoni}

Faculty of Informatics

Università della Svizzera italiana,

USI

monica.landoni@usi.ch

Elisa Rubegni

Department of Business

Economics, Health and Social Care

University of Applied Sciences and

Arts of Southern Switzerland,

SUPSI

elisa.rubegni@supsi.ch

\section{Emma Nicol}

Department of Computer and

Information Sciences

University of Strathclyde, UK

Emma.nicol@strath.ac.uk

\section{Janet Read}

Child-Computer Interaction Group

University of Central Lancashire

Preston | UK | PR1 2HE

JCRead@uclan.ac.uk

\begin{abstract}
This workshop explores the many roles children can play in the design of technology for their own use.

Much literature has reported on how children have been mainly playing co-designer roles. By looking closer it emerges that children have mostly been involved in the ideation phase of design. More rarely were they actively engaged in other design phases e.g. conducting Contextual Inquiry, elaborating User Data Analysis, producing Personas, preparing Sketches and Story Boards and crafting Low and High resolution

Prototypes. When it comes to evaluation, children are still mostly considered as final users while only rarely are they invited to run heuristic evaluations or even to have a more active role during the process. We would like to invite all relevant stakeholders: researchers, teachers, parents, and of course children, to share their experiences. The purpose of the workshop is also to bring their open questions and requests for guidelines and suggestions as to when and how to involve children in the various process stages. We hope to produce good definitions of the many roles children can play as co-researchers as well as to explore the benefits each participant will get from engaging with the overall design experience.
\end{abstract}




\section{Author Keywords}

Design stages; ideation; personas; prototypes; coresearchers, design experience.

\section{ACM Classification Keywords}

H.5.2. Information interfaces and presentation.

\section{Motivation}

The aim of this workshop is to delve deeply into the roles that children can play at the various stages of design, from informants to participants (Druin, 2002; Read, 2015) to co-researchers, by examining the pros and cons, and considering how this can truly be achieved. During the last decades many efforts have been taken in the direction of including children's perspectives in the design of digital artifacts. A number of methodological approaches have been developed in order to ensure children can effectively contribute to the design process. In what follows, we provide a very brief overview of some particularly meaningful contributions from the literature. We start from the considerations on participatory design with children by Read et al (2002) together with the cooperative inquiry approach by Druin (1999) then revisited by Guha et al (2013). Then we move on to specific approaches for engaging children by using comics (Maraveji et al, 2007) or asking children to draw characters as "fictitious cartoon personalities" (Grundy et al, 2012) in order to help them deal with the emotional perspective of design. The ecological dimension of design is catered for by using an obstructed theatre approach (Read et al, 2010) where details of the new technology to be designed are disclosed via discussion and enactment of actors without revealing too much and risking a bias in users. The paper describes how and how effectively children could play the actor roles. The use of shared narratives to support children during the co-design activities is described by Dindler et al (2005) who present their Mission from Mars approach. Fitton at all (2015) go a step further and explore how children can engage with maker technologies in order to produce design ideas. Colombo and Landoni, (2013) instead compare the effects of using pen and paper versus tablets on the overall ideation process. Among the many open issues under discussion in our research community is how to give children's opinion the right importance and consideration (Read et al, 2014). In this space van Doorn e al, $(2013 ; 2014)$ have studied how children could be considered as research collaborators at many different stages of research. On similar lines, Salian et al (2013) debate on how children could act as heuristic evaluators. In the Pads project (Rubegni et al, 2014) children mainly acted as evaluators of the different versions of the application by producing multimedia stories at school.

This very concise review shows how our community is buzzing with novel approaches to help children be engaged in the most fruitful and effective way with the various design perspectives and stages. This workshop will provide a venue for stakeholders to share precious details, tricks and tips, that come only with experience and field work. This workshop will enable us to explore and identify the main research trends beyond existing literature by exchanging views, experiences and good practice examples with participants willing to share more than what usually goes into a research paper. The aim is to explore further the different roles children can play within the design process. In particular, we are looking for contributions that offer a perspective on the approaches, techniques and methods that allow children's engagement. 
Indeed, the workshop will be an opportunity to delineate the actual scene regarding different aspects, such as:

- Context: formal (mainly schools and educational institutions) informal (libraries or other non-educational formal setting) and nonformal (home and any leisure-related locations).

- Stakeholders: their aims and objectives as well as preferred methods and techniques to get children engaged with different tasks and activities.

- Benefits: what are the advantages for each stakeholder in directly and indirectly engaging children?

- Effect on children: how these approaches affect children and the other stakeholders, as well as the process itself.

The scope of the workshop is the current research in Children's Design (CD) and the trend towards engaging children beyond ideation and beyond early prototyping stages by giving them a more active role compared with earlier design research.

\section{Objectives}

The workshop will allow participants to be engaged in a fruitful discussion around this issue and to create synergies among the attendees. We look for relevant contributions on different aspects: theoretical, methodological, technological, and practical. We would like to hear from researchers, teachers, parents and children who have been or plan to be involved with children's design activities that involve children directly in different roles. We are keen to discuss the inevitable ethical issues emerging as well as the costs and benefits of such trends.

We aim to discuss a series of topics, among those:

- Ethics in children design research

- Children as makers

- Children as expert evaluators

- Children conducting Contextual Enquiry activities

- Children and the emotional and ecological dimensions of design

- Children and paper prototyping

- Benefits and educational value of children playing an active role in $C D$

- Can children be researchers?

This workshop will be run together with the 'Being Explicit about Underlying Values, Assumptions and Views when Designing for Children in the IDC

Community' workshop. This will enable our participants to share their views and engage with those of this very closely related workshop. The merged workshop will be open to up to 30 people and will last a full day.

Potential participants will submit a position paper to the organizers by using the conference extended abstract template. Once that has been reviewed and accepted each attendee will present their own contribution ( 2 minutes). This way the two groups will become familiar with each other's ideas, perspectives and approaches. By the end of the morning we will have two sets of topics to be further discussed in the afternoon. Our schedule will encourage participants to collaborate across groups but also allow them space to delve deeply into the two specific facets of the merged workshop according to the following schedule: 


\begin{tabular}{|c|c|}
\hline 9.00 & Introduction and background \\
\hline 9.30 & Two minutes presentations by participants \\
\hline 10.30 & Coffee Break \\
\hline 11.00 & $\begin{array}{l}\text { Discuss examples of design cases or projects in } \\
\text { relation to values and/or roles in mixed groups } \\
\text { of } 3-4 \text { people. }\end{array}$ \\
\hline 12.00 & $\begin{array}{l}\text { Short presentations and wrap-up of the } \\
\text { morning }\end{array}$ \\
\hline 12.30 & Lunch Break \\
\hline 13.30 & Values Workshop (parallel session) \\
\hline 13.30 & $\begin{array}{l}\text { Roles Workshop (parallel session): Group } \\
\text { discussion on existing and emerging guidelines } \\
\text { to drive the choice of roles to be played by } \\
\text { children. What, who, when and how plus points } \\
\text { coming from presentations given in the } \\
\text { morning. }\end{array}$ \\
\hline 15.30 & Coffee Break \\
\hline 16.00 & $\begin{array}{l}\text { Wrapping up of the afternoon program and } \\
\text { production of poster to sum up emerging } \\
\text { definitions and guidelines (plenary) }\end{array}$ \\
\hline 17.00 & End of Workshop \\
\hline
\end{tabular}

The organizers will facilitate plenary discussion and group work.

\section{Expected Outcome}

Our goal in the workshop is to explore the landscape within research and practice in this field in order to provide an agenda for future work. In particular, via the plenary and sub-group discussions we expect to identify a set of definitions and guidelines as we recognise a number of open issues to be put on the table for further investigation. The wrapping up of the event will provide as outcome a poster summing up our major achievements in the form of definitions and guidelines.

\section{Call for Participation}

Children can play many roles in the design of technology for their own use. By looking closer at available literature it emerges that children have mostly been involved in the ideation phase of design. More rarely were they actively engaged in other design phases e.g. conducting Contextual Inquiry, elaborating User Data Analysis, producing Personas, preparing Sketches and Story Boards and crafting Low and High resolution Prototypes. When it comes to evaluation, children are still mostly considered as final users while only rarely are they invited to run heuristic evaluations or even to have a more active role during the process. We would like to invite all relevant stakeholders: researchers, teachers, parents, and of course children, to share their experiences. We want to identify the main research trends beyond existing literature by exchanging views, experiences and good practice examples with participants willing to share more than 


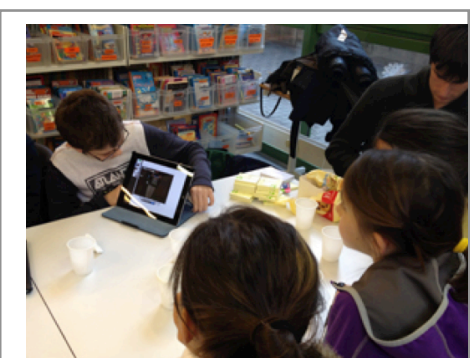

Figure 1 Children in a codesign phase in a school library

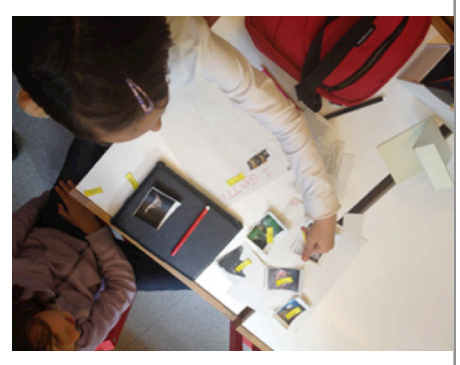

Figure 2 Children collaborating in designing an enhanced eBook

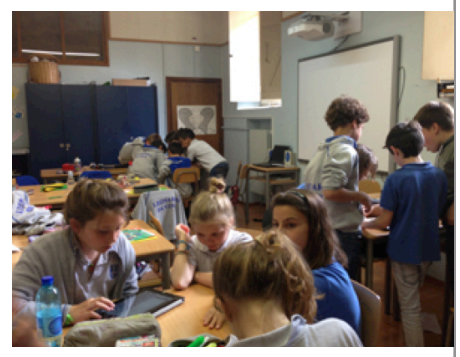

Figure 3 Children during the evaluation of a prototype at school what usually goes in a research paper. Come and share precious details, tricks and tips, which come only with experience and field work.

We invite contributions on:

- Ethics in children design research

- Children as makers

- Children as expert evaluators

- Children conducting Contextual Enquiry activities

- Children and the emotional and ecological dimensions of design

- Children and paper prototyping

- Benefits and educational value of children playing an active role in $C D$

- Can children be researchers?

Potential participants are asked to submit a position paper to the organizers by using the conference extended abstract template. Once that has been reviewed and accepted they will be invited to present their contribution ( 2 minutes). Through the plenary and sub-group discussions we will identify a set of definitions and guidelines as we recognise a number of open issues to be put on the table for further investigation.

\section{Organisers (short bios)}

Monica Landoni is a senior researcher at the faculty of Informatics at Università della Svizzera italiana, USI. She has worked on a number of national and European projects investigating how technology can support children when searching, writing and reading for education and pleasure. While doing that she has happily survived the design and running of many codesign sessions in formal and informal settings and is looking forwards having more in the future.

Emma Nicol is a researcher in the Computer and Information Sciences Department of the University of Strathclyde, Glasgow. She has conducted ethnographic research investigating how children find and use information and research on children's use of museum interactives. She recently completed an EPSRC-funded project investigating the design of mobile interfaces for older people using participatory design.

Elisa Rubegni is a researcher at the Department of Business Economics, Health and Social Care at University of Applied Sciences and Arts of Southern Switzerland. She investigates the sociotechnical issues created by information systems and her agenda is focused on two main topics: technology in education and interaction design and children. She has been involved in many projects (national and European) in which she conducted research concerning the design of digital technology for supporting human cognitive processes.

Janet Read is a professor of CCI concerned both with evaluation and design as it applies to IDC and has a particular interest in the ethical participation of children in IDC research. She has recently worked on projects 
on serious games design for children, on the design of cool for teenagers and on culturally sensitive PD.

\section{References}

1. Luca Colombo and Monica Landoni (2013) Low-tech and High-tech Prototyping for eBooks Co-design with Children. IDC'13. 289-292.

2. Christian Dindler, Eva Eriksson, Ole Sejer Iversen, Andreas Lykke-Olesen Martin Ludvigsen (2005) Mission from Mars - A Method for Exploring User Requirements for Children in a Narrative Space. IDC'05. 40-47.

3. Alison Druin (2002) The role of children in the design of new technology. Behaviour and Information technology 21(1). 1-25.

4. Alison Druin (1999) Cooperative Inquiry: developing new technologies for children with children. Proceedings of the SIGCHI conference on Human Factors in Computing Systems. ACM. 592599.

5. Daniel Fitton, Janet C Read, John Dempsey (2015) Exploring Children's Designs for Maker Technologies. IDC'15. 379-382.

6. Cathy Grundy, Lyn Pemberton, Richard Morris (2012) Characters as Agents for the Co-Design Process. IDC'12. 180-183.

7. Mona Leigh, Guha, Alison Druin, Jerry Alan Fails (2013) Cooperative Inquiry revisited: Reflections of the past and guidelines for the future of intergenerational co-design. International Journal of Child-Computer Interaction. 14-13.

8. Neema Moraveji, Jason Li, Jiarong Ding, Patrick O'Kelley, Suze Woolf (2007) Comicboarding: Using Comics as Proxies for Participatory Design with Children. IDC'07. 1371-1374.

9. Janet C Read. 2015 Children as Participants in Design and Evaluation. Interactions, March-April. 64-66.
10. Janet C Read, Peggy Gregory, Stuart MacFarlane, Barbara McManus, Peter Gray, Ray Patel (2002) An Investigation of Participatory Design with ChildrenInformant, Balanced and Facilitated Design. Interaction Design and Children.

11. Janet $C$ Read, Daniel Fitton, Matthew Horton (2014) Giving Ideas an Equal Chance: Inclusion and Representation in Participatory Design with Children. IDC'14. 105-114.

12. Janet $C$ Read, Daniel Fitton, Emanuela Mazzone (2010) Using Obstructed Theatre with Child Designers to Convey Requirements. CHI 2010. 4063-4068.

13. Elisa Rubegni and Monica Landoni. 2014. Fiabot! design and evaluation of a mobile storytelling application for schools. In Proceedings of the 2014 conference on Interaction design and children (IDC '14). ACM, New York, NY, USA, 165-174.

DOI=http://dx.doi.org/10.1145/2593968.2593979.

14. Kishan Salian, Gavin Sim, Janet C Read (2013) Can children Perform a Heuristic Evaluation? APCHI'13. 137-141.

15. Fenne van Doorn, Pieter Jan Stappers, Mathieu Gielen (2013) Design Research by Proxy: using Children as Researchers to gain Contextual Knowledge about User Experience. CHI'13. 28832891.

16. Fenne van Doorn, Mathieu Gielen, Pieter Jan Stappers (2014) Children as Co-Researchers: More than Just a Role-Play. IDC'14. 237-240. 